\title{
The importance of solvent reorganisation in the effect of an ionic liquid on a unimolecular substitution process $\uparrow$
}

\author{
Hon Man Yau, ${ }^{a}$ Susan A. Barnes, ${ }^{b}$ James M. Hook, ${ }^{c}$ Tristan G. A. Youngs, ${ }^{d}$ \\ Anna K. Croft ${ }^{* b}$ and Jason B. Harper $* a$
}

Received (in Cambridge, UK) 28th March 2008, Accepted 30th April 2008

First published as an Advance Article on the web 9th June 2008

DOI: $10.1039 / \mathbf{b 8 0 5 2 5 5 g}$

\begin{abstract}
Temperature dependent rate studies demonstrate an enthalpic benefit and an entropic cost associated with the change in the rate of a unimolecular substitution process on addition of a high proportion of an ionic liquid, the latter effect being supported by molecular dynamics simulations.
\end{abstract}

Ionic liquids have been touted as potential alternatives to environmentally damaging volatile organic solvents. ${ }^{1}$ These salts, typically made up of a bulky organic cation and a charge diffuse anion, 2,3 are attractive as alternative solvents due to their negligible vapour pressures and the ability to 'tune' the properties of the solvent based on the modification of the component ions. 3,4

The major focus of research into the use of ionic liquids as solvents has been processes with industrial relevance. ${ }^{5}$ Differences in the rates and selectivities of the processes are often observed when compared with the corresponding reactions in molecular solvents, however, there are only limited reports detailing the origins of the changes. ${ }^{6} \ddagger$ This contrasts with the extensive understanding of the effect on reaction outcome on changing from one molecular solvent to another. ${ }^{7}$

We have developed a research programme that seeks to understand the origin of the effects of ionic liquids on organic processes. Our initial experimental studies in this area ${ }^{8}$ have focused on the unimolecular substitution of the chloride $\mathbf{1}$ in systems containing different proportions of an ionic liquid, 1-butyl-3-methylimidazolium $\left([\mathrm{Bmim}]^{+}\right)$bis(trifluoromethanesulfonyl)imide $\left(\left[\mathrm{N}\left(\mathrm{CF}_{3} \mathrm{SO}_{2}\right)_{2}\right]^{-}\right)$(Scheme 1). The effect demonstrated for the substrate $\mathbf{1}$ was that there was an initial increase in the rate of reaction with ionic liquid concentration, followed by a subsequent decrease. A hypothesis that might account for the observed rate changes is that the addition of small amounts of ionic liquid acts to stabilise the transition

\footnotetext{
${ }^{a}$ School of Chemistry, University of New South Wales, Sydney,

NSW,2052,Australia.E-mail: j.harper@unsw.edu.au;

Fax: + 6129385 6141; Tel: + 61293854692

${ }^{b}$ School of Chemistry, University of Wales Bangor, Bangor, Gwynedd, UK LL572UW.E-mail: a.k.croft@bangor.ac.uk;

Fax: + 441248 370528; Tel: + 441248382391

${ }^{c}$ Analytical Centre, University of New South Wales, Sydney, NSW, 2052, Australia

${ }^{d}$ Atomistic Simulation Centre, School of Mathematics and Physics, Queen's University, Belfast, UK BT7 1NN

$\dagger$ Electronic supplementary information (ESI) available: Eyring plot for the data represented in Table 1, description of computational methodology for Fig. 1, probability distribution for the components of the ionic liquid around tert-butyl chloride, sample radial distribution functions to demonstrate ordering, analysis of literature data using bimolecular form of the Eyring equation. See DOI: 10.1039/b805255g
}

state leading to the ion-pair intermediate. Upon further increasing the proportion of the ionic liquid, the magnitude of the interactions between components of the solution increases, meaning that the requirement of any solvent reorganisation would also increase. Described herein are studies to test this proposition.

The methanolysis of the chloride $\mathbf{1}$ was observed as described previously ${ }^{8}$ in solutions containing either $0 \%$, $c a .12 \%$ or $c a .90 \%$ of the $[\mathrm{Bmim}]\left[\mathrm{N}\left(\mathrm{CF}_{3} \mathrm{SO}_{2}\right)_{2}\right]$ by volume over a range of temperatures. These concentrations, which correspond to mole fractions of ionic liquid of $\chi=0,0.02$ and 0.50 , respectively, were chosen as they represent neat molecular solvent, the solvent mixture which previously showed the greatest rate for the reaction and the concentration of ionic liquid which gave a rate of reaction the same as for neat methanol. From the kinetic data obtained, Eyring plots ${ }^{9}$ were generated and values for the activation parameters, $\Delta H^{\ddagger}$ and $\Delta S^{\ddagger}$, were calculated (Table 1).

The values for the activation parameters do not change, within the limits of experimental error, on addition of a small amount (0.02 mol fraction) of ionic liquid to the reaction mixture. On addition of large quantities of ionic liquid $(0.50$ mol fraction) there are dramatic changes in the activation parameters, even though at $313 \mathrm{~K}$ the rates of reactions at $\chi=$ 0 and 0.50 ionic liquid are the same within error. ${ }^{8}$ There is a significant decrease in the activation enthalpy, as is consistent with stabilisation of the incipient charges in the transition state. At the same time, there is a dramatic change in the activation entropy, indicating that there is a major increase in organisation on going to the transition state. Such a value suggests that there is significant reorganisation of the components of the solvent around the substrate as reaction occurs due to the interactions between the ions of the ionic liquid and the developing charges on the substrate. $\|$

From the above discussion, there are opposing effects on the rate of reaction of the substrate $\mathbf{1}$ upon addition of ionic liquid

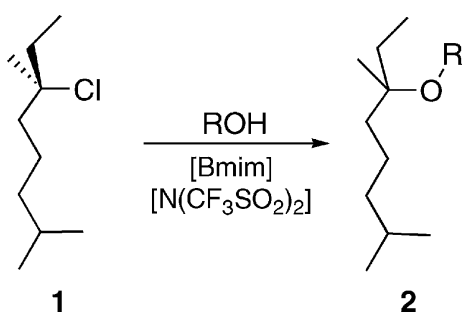

Scheme 1 Nucleophilic substitution of the chloride 1 to give the ether $\mathbf{2}$, carried out in a mixture of alcohol and ionic liquid.§ 
Table 1 Activation parameters for the unimolecular substitution of

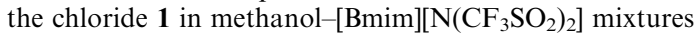

\begin{tabular}{llc}
\hline$\chi_{\text {Ionic liquid }}$ & $\Delta H^{\ddagger} / \mathrm{kJ} \mathrm{mol}^{-1 a}$ & $\Delta S^{\ddagger} / \mathrm{J} \mathrm{K}^{-1} \mathrm{~mol}^{-1 a}$ \\
\hline 0 & $97.3 \pm 0.5$ & $-22 \pm 2$ \\
0.02 & $97.6 \pm 3.8$ & $-18 \pm 12$ \\
0.50 & $43.4 \pm 5.8$ & $-194 \pm 18$ \\
${ }^{a}$ Uncertainties quoted are standard deviations. & \\
\hline
\end{tabular}

to the reaction mixture, favouring the reaction in terms of activation enthalpy and disfavouring it in terms of activation entropy. However, it is not clear from the data what is the source of the increase observed, both previously ${ }^{8}$ and in these studies, in reaction rate on going from $\chi=0$ to $\chi=0.02$ ionic liquid. Given the effect of high concentrations of ionic liquid, it is reasonable to suggest that, at low concentrations of ionic liquid, both effects are occurring but that the stabilisation of the transition state dominates.** This is supported by the observation that on addition of an equivalent amount of lithium bis(trifluoromethanesulfonyl)imide to the reaction mixture, a $c a$. three-fold rate enhancement was observed at $313 \mathrm{~K}$; similar temperature dependence studies to those described above show stabilisation of a slightly more ordered transition state $\left(\Delta H^{\ddagger}=83.0 \pm 2.6 \mathrm{~kJ} \mathrm{~mol}^{-1}, \Delta S^{\ddagger}=-60 \pm 8 \mathrm{~J}\right.$ $\left.\mathrm{K}^{-1} \mathrm{~mol}^{-1}\right)$. The greater magnitude of the effect is not surprising given the smaller cation involved in this case and highlights that a simple inorganic salt is likely to have a greater effect than an ionic liquid.

Molecular dynamics simulations have been used extensively to study properties of imidazolium based ionic liquids, ${ }^{10}$ particularly to examine the ordering of components of the solution about dissolved substrates. ${ }^{11}$ In this case such methods also offer the ability to examine the extreme case not available experimentally with neat ionic liquid as the solvent. Simulations using tert-butyl chloride as a simple model for the substrate $\mathbf{1}$ in the model ionic liquid 1,3-dimethylimidazolium hexafluorophosphate $[\mathrm{Mmim}]\left[\mathrm{PF}_{6}\right]^{11}$ show negligible ordering in solutions of the starting material but this is dramatically increased about the cation intermediate (Fig. 1). This suggests significant ordering of the solution (particularly the cation) around the energetically closely-related transition state and is qualitatively consistent with the entropies of activation observed above.

It is worthwhile to note that in previous studies of the activation parameters of substitution processes ${ }^{12}$ the reactions involved charged nucleophiles. The transition state thus involves charge dispersion rather than charge separation. Comparison with these results is possible, though it should be noted that the authors have used the unimolecular form of the Eyring equation in their analysis. When their data is reanalysed using the bimolecular form, the enthalpies of activation are consistent with a significant degree of ion pairing between the components of the ionic liquid and the charged nucleophile, as would be anticipated for stabilisation of the developing charges as discussed here. Similarly, the entropies of activation are consistent with an environment that supports ion pairing.

In conclusion, it has been demonstrated for a unimolecular substitution process that the addition of a high proportion of

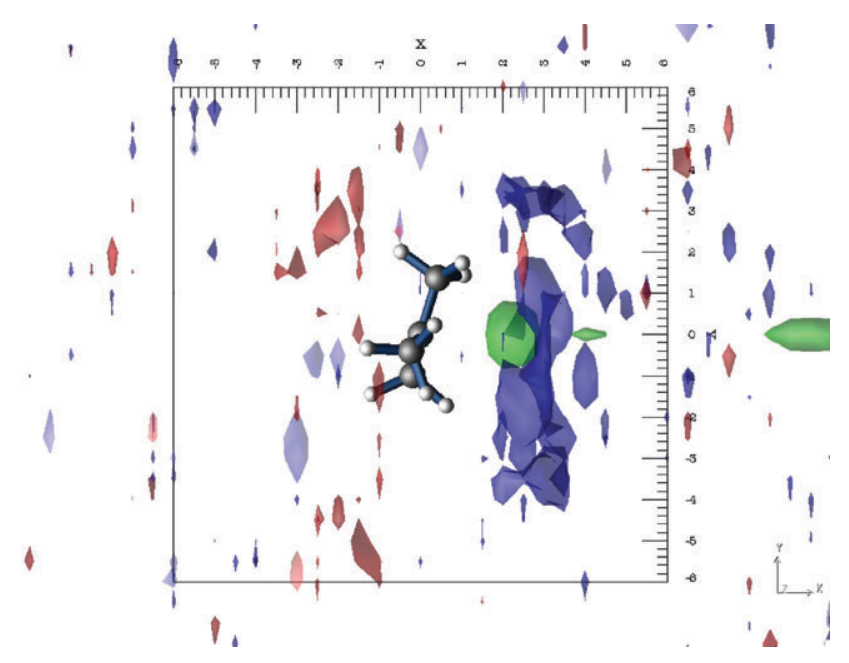

Fig. 1 Ordering of the components of $[\mathrm{Mmim}]\left[\mathrm{PF}_{6}\right]$ about the tertbutyl cation-chloride anion pair. Areas in red are more likely to contain the anion, those in blue are more likely to contain the cation while the localised chloride is shown in green.

an ionic liquid results in significant solvent reorganisation and both an enthalpic benefit and an entropic cost to the rate of the reaction. This suggests that in related systems, for which there is significant charge development in the transition state, a similar interplay of effects may occur. In such cases the solvent mixture may be adjusted to maximise the rate of reaction in a predictable fashion and studies are underway in this area.

AKC would like to thank the Royal Society for a travel grant to visit JBH and JBH would like to thank UNSW for financial support through the Faculty Research Grant programme.

\section{Notes and references}

$\ddagger$ There are specific cases where the reactivity of the components of an ionic liquid, ${ }^{13}$ particularly through the use of protic cations ${ }^{14}$ and basic anions ${ }^{15}$ alters the reaction outcome. These cases do not rely on fundamental properties of the ionic liquid and will not be referred to further here.

$\S$ The enantioenriched chloride $\mathbf{1}$ was used as it was readily available in our laboratories; the racemate may equally well be used as the stereochemistry does not affect the ability of the chloride ion to leave. - In a typical experiment, a sample of the chloride 1 ( $c a .50 \mathrm{mg}$, prepared as described previously $\left.{ }^{16}\right)$ was dissolved in a mixture of [Bmim $]\left[\mathrm{N}\left(\mathrm{CF}_{3} \mathrm{SO}_{2}\right)_{2}\right]$ and methanol $(3.5 \mathrm{~mL})$ followed by addition of triethylamine $(0.1 \mathrm{~mL})$. The sample was held at either $303,313,323$ or $333 \mathrm{~K}$ in a Bruker DMX500 spectrometer operating at $c a .49 \mathrm{MHz}$ and a ${ }^{35} \mathrm{Cl}$ NMR spectrum was acquired every $28 \mathrm{~min}$. The integration of the chloride signal was correlated with time and first order rate constants for the release of chloride were determined.

$\|$ During review, the decrease in apparent polarity of the system on addition of the relatively non-polar [ $\mathrm{Bmim}]\left[\mathrm{N}\left(\mathrm{CF}_{3} \mathrm{SO}_{2}\right)_{2}\right]$ was raised as an alternative reason for the decrease in the observed rate. However, our previous results ${ }^{8}$ show limited correlation between the rate of reaction and apparent polarity of the system and the results presented here indicate a decrease in the activation enthalpy on addition of an ionic liquid. This is inconsistent with the polarity argument, which involves destabilisation of the transition state on going to the less polar ionic liquid.

** That is, a classical 'salt effect ${ }^{17}$ is being observed.

1. R. D. Rogers and K. R. Seddon, Science, 2003, 302, 792.

2. C. L. Hussey, Pure Appl. Chem., 1988, 60, 1763; R. H. Dubois, M. J. Zaworotko and P. S. White, Inorg. Chem., 1989, 28, 2019; J. S. Wilkes and M. J. Zawarotko, J. Chem. Soc., Chem. Commun., 1992, 965. 
3. P. Bonhôte, A. Das, N. Papageorgiou, K. Kalanasundram and M. Grätzel, Inorg. Chem., 1996, 35, 1168; J. G. Huddleston, H. D. Willauer, R. P. Swatloski, A. E. Visser and R. D. Rogers, Chem. Commun., 1998, 1765.

4. H. Stegemann, A. Rhode, A. Reiche, A. Schnittke and H. Füllbier, Electrochim. Acta, 1992, 37, 379; A. Elaiwi, P. B. Hitchcock, K. R. Seddon, N. Srinivasan, Y.-M. Tan and T. Welton, J. Chem. Soc., Dalton Trans., 1995, 3467; K. R. Seddon, Kinet. Catal., 1996, 37, 693; K. R. Seddon, J. Chem. Technol. Biotechnol., 1997, 68, 351.

5. T. Welton, Chem. Rev., 1999, 99, 2071; R. A. Sheldon, R. M. Lau, M. J. Sorgedrager and F. van Rantwijk, Green Chem., 2002, 4, 147; J. Dupont, R. F. de Souza and P. A. Z. Suarez, Chem. Rev., 2002, 102, 3667.

6. J. B. Harper and M. N. Kobrak, Mini-Rev. Org. Chem., 2006, 3, 253.

7. M. B. Smith and J. March, March's Advanced Organic Chemistry, Wiley-Interscience, New York, 2001.

8. B. Y. W. Man, J. M. Hook and J. B. Harper, Tetrahedron Lett., 2005, 46, 7641.

9. H. Eyring, J. Chem. Phys., 1935, 3, 107.

10. R. M. Lynden-Bell, M. G. Del Pópolo, T. G. A. Youngs, J. Kohanoff, C. G. Hanke, J. B. Harper and C. C. Pinilla, Acc. Chem. Res., 2007, 40, 1138.
11. C. G. Hanke, A. Johansson, J. B. Harper and R. M. Lynden-Bell, Chem. Phys. Lett., 2003, 374, 85; J. B. Harper and R. M. LyndenBell, Mol. Phys., 2004, 102, 85.

12. N. L. Lancaster, J. Chem. Res., 2005, 413; N. L. Lancaster and T. Welton, J. Org. Chem., 2004, 69, 5986; N. L. Lancaster, P. A. Salter, T. Welton and G. B. Young, J. Org. Chem., 2002, 67, 8855 .

13. J. R. Harjani, S. J. Nara and M. M. Salunkhe, Tetrahedron Lett., 2002, 43, 1127; V. K. Aggarwal, I. Emme and A. Mereu, Chem. Commun., 2002, 1612; H.-P. Nguyen, H. Matondo and M. Baboulène, Green Chem., 2003, 5, 303; J. Gui, Y. Deng, Z. Hu and Z. Sun, Tetrahedron Lett., 2004, 45, 2681.

14. S. S. Palimkar, S. A. Siddiqui, T. Daniel, R. J. Lahoti and K. V. Srinivasan, J. Org. Chem., 2003, 68, 9371; H. Zhang, F. Xu, X. Zhou, G. Zhang and C. Wang, Green Chem., 2007, 9, 1208.

15. J.-M. Xu, Q. Wu, Q.-Y. Zhang, F. Zhang and X.-F. Lin, Eur. J. Org. Chem., 2007, 1798; B. C. Ranu, R. Jana and S. Sowmiah, J. Org. Chem., 2007, 72, 3152.

16. P. Müller and J. C. Rossier, J. Chem. Soc., Perkin Trans. 2, 2000, 2232.

17. L. C. Bateman, M. G. Church, E. D. Hughes, C. K. Ingold and N. A. Taher, J. Chem. Soc., 1940, 979. 